UCRL- CR-112568

PREPRINT

B192560

\begin{abstract}
Report on the Work "Nonparaxial MHD Stabilizers for an Axisymmetric Magnetic Mirror
\end{abstract}

Dmitri Ryutov

et al.

Month1y Report

under Purchase Order B192560

December 1992






\section{DISCLAIMER}

Work performed under the auspices of the U.S. Department of Energy by Lawrence Livermore National Laboratory under contract number W-7405-ENG-48.

This document was prepared as an account of work sponsored by an agency of the United States Government. Neither the United States Government nor the University of California nor any of their employees, makes any warranty, express or implied, or assumes any legal liability or responsibility for the accuracy, completeness, or usefulness of any information, apparatus, product, or process disclosed, or represents that its use would not infringe privately owned rights. Reference herein to any specific commercial products, process, or service by trade name, trademsirk, manufacturer, or otherwise, does not necessarily constitute or imply its endorsement, recommendation, or favoring by the United States Government or the University of California. The views and opinions of authors expressed herein do not necessarily state or reflect those of the United States Government or the University of California, and shall not be used for advertising or product endorsement purposes. 
Report on the Work

"Nonparaxial MHD Stabilizers for an Axisymmetric Magnetic Mirror"

\author{
Dmitri Ryutov, et al. \\ Institute of Nuclear Physics \\ Novosibirsk, Russia
}

\title{
Theoretical Activity
}

The analysis of the MHD stability of flute perturbations in axisymmetric nonparaxial mirrors has been started. The preliminary screening of the possible candidates to the role of a stabilizer has been made. The following candidates have remained: nonparaxial sections near the ends of a long uniform solenoid (one can expect some stabilizing effect in the presence of sloshing ions); divertor-like configuration, similar to the one used for other purposes in the experiments on "TARA"; the cusp stabilizer. The first two candidates are attractive as they can provide stability of a long axisymmetric mirror "by itself", without attaching to it any external stabilizing cells; the third candidate gives almost a $100 \%$ guarantee of stabilization but needs large scale high field coils for the ring cusp. Special attention was paid to the stability of the global $m=1$ mode. Some general observations regarding the geometric properties of the magnetic field which allow the stability of the global mode, have been made (the presence of two null-points outside the separatrix). September will be devoted to the preparing of the preliminary report on the conclusions drawn (to be sent to the Technical Representative at the beginning of October).

The populations of fast particles play an important role in a number of schemes of the mirror devices (e.g., in the mirror based neutron sources). Their drift frequency around the magnetic axis can easily exceed the characteristic growth rate of the flute perturbations. To analyse their contribution to the energy principle, one has to generalize the latter, with the account of the fast drift motion. Recently, a convenient form of the generalized energy principle has been proposed by Ryutov and Lansky (INP). This August was devoted to the analysis of axisymmetric configurations, basing on this principle. The draft of the paper based on the stability analysis of axisymmetric configurations will be prepared during September and mailed to the Technical Representative for permission on publication at the end of the month. 


\section{Experimental Activity}

The experimental part of the work was started by preparations for the experiments on a plasma equilibrium response to externally applied small magnetic field in MHD-anchor region. Initial theoretical estimates have shown that a small transverse disturbance of dipole type applied in this region causes a shift of a plasma column in equilibrium from geometrical axis which is inversely proportional to a pressure-weighted curvature averaged along the machine. It can be used for direct measurements of this quantity for MHDstabilizers of different types. We performed the simulation runs for the parameters of GDT-facility and found out that a few gauss perturbation is sufficient for measurement as it causes the shift of order of a plasma radius in the midplane. During this month a pair of co-axis coils with a $0.95 \mathrm{~m}$ radius were installed on the end tank of the GDT-machine and electrical and mechanical tests were performed. This coils produce nearly homogeneous magnetic field inside the expander region which can be varied up to 100 gauss. The linear array of Langmiur probes were placed in the end tank at the position with the magnetic field strength which equals to that at the midplane (appr. $40 \mathrm{~cm}$ from the mirror coil position). It will be used to measure the displacement of the plasma column.

Preliminary experiments with the energizing of the coils and measurements of the equilibrium response were started 08/27/1992. Initial experimental data indicate that the gun produced plasma column off-axis displacement after the build-up phase is small and satisfactorily reproducible for different shots that allows to start systematic runs.

The next month will be devoted to the systematic measurements of plasma displacements and their preliminary interpretation. 


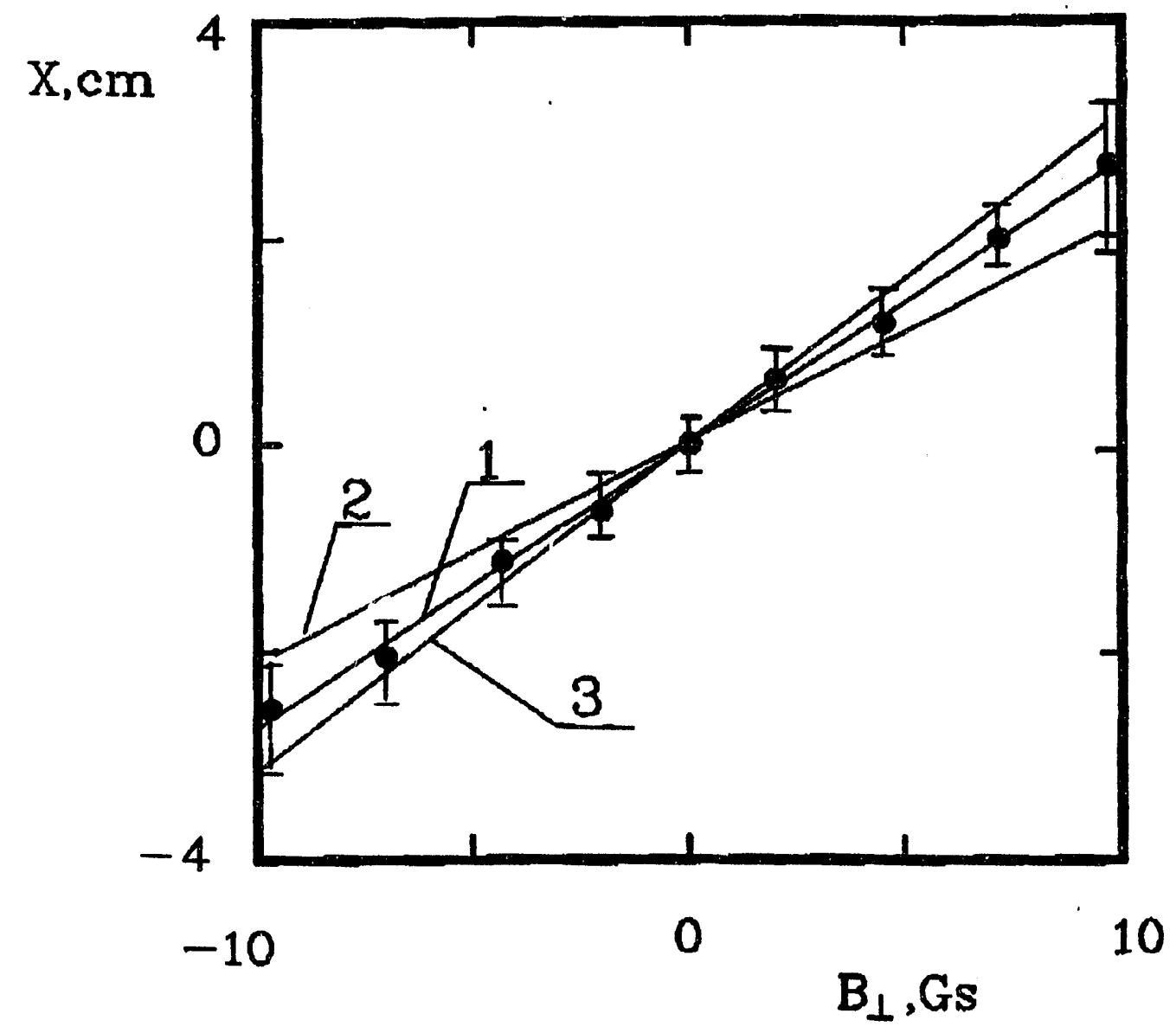

Figure 1: Displacement of Plasma Column vs Amplitude of Disturbance 

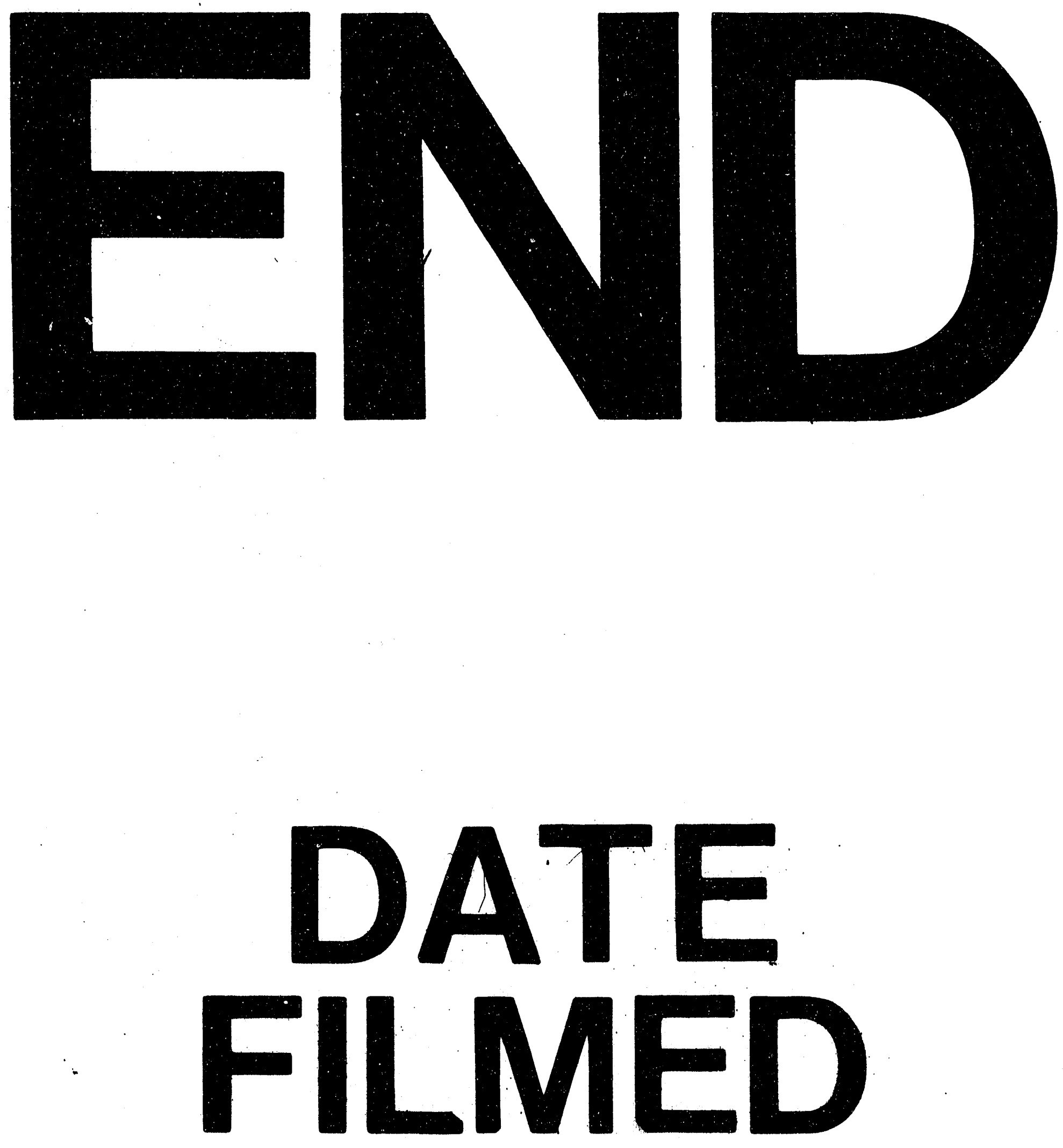

1

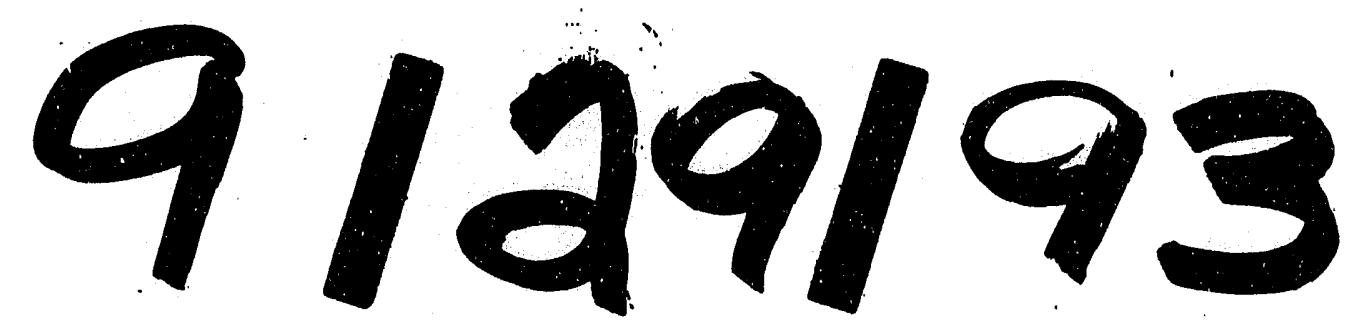


